\title{
PIBID Inglês no Paraná: crenças e metáforas sobre ensino/aprendizagem de inglês e formação de professores
}

\author{
PIBID in Paraná: beliefs about teaching/learning English \\ and teacher education
}

\author{
PIBID Inglés en Paraná: creencias y metáforas sobre \\ enseñanza/aprendizaje de inglés y formación de profesores
}

\author{
Thaisa de Andrade Jamoussi ${ }^{1}$ \\ Gisele Werneck Divardin ${ }^{2}$
}

\begin{abstract}
RESUMO: Este artigo apresenta as crenças, expressas ou não por metáforas linguísticas convencionais, sobre os processos de ensino/aprendizagem de inglês e formação inicial e continuada de professores de inglês nos subprojetos Programa Institucional de Bolsa de Iniciação à Docência (PIBID) Inglês e acomodá-las dentro de metáforas conceituais reveladas no estudo de Audi et al. (2013). Os dados incluem resumos e resumos expandidos publicados pelos subprojetos PIBID Inglês de seis universidades estaduais do estado do Paraná e da Universidade Federal do Paraná em 2015 e 2016. A geração de dados utilizou os anais dos seguintes eventos acadêmicos: $1^{\circ}$ PIBIDSUL / PARFORSUL / ENLICSUL, V SEMINÁRIO NACIONAL DO PIBID e VI $C L A F P L$. O referencial teórico que serviu de suporte para a análise foram os estudos sobre crenças de Barcelos (2004, 2007), nos estudos sobre metáforas de Lakoff e Johnson (1980) e no estudo de Audi et al. (2013). A análise corroborou os metáforas do estudo de Audi et al. (2013) e demonstrou a existência de mais duas crenças expressas nas metáforas OS GENEROS TEXTUAIS SÃO A REALIDADE e JOGAR E BRINCAR É APRENDER. Estudos como este são importantes, pois demonstram como as crenças influenciam os processos de ensino/aprendizagem de inglês e formação de professores de inglês. Outra contribuição da pesquisa é o mapeamento dos estudos realizados sobre os subprojetos PIBID Inglês que nos últimos anos têm contribuído para a formação inicial e continuada de professores.
\end{abstract}

PALAVRAS-CHAVE: PIBID. Inglês. Ensino/aprendizagem de inglês. Formação de professores. Crenças e metáforas.

\footnotetext{
${ }^{1}$ Professora da disciplina de Estágio Curricular Supervisionado em Língua Inglesa do Curso de Licenciatura em Letras da Universidade Estadual de Ponta Grossa - UEPG. Pesquisa desenvolvida durante licença sabática (outubro de 2016 a março de 2017) com o acompanhamento da

2 Professora Doutora Gisele Werneck Divardin da Universidade Tecnológica Federal do Paraná, Campus de Ponta Grossa.
} 
ABSTRACT: This article presents the beliefs, expressed or not by linguistic conventional metaphors, about the processes of teaching/learning English and initial and continuing education of English teachers involved in the subprojects of the Institutional Program of Scholarship for Initiation in Teaching (PIBID, in the Portuguese acronym) and accommodate them in the conceptual metaphors revealed in the study by Audi et al (2013). The data included abstracts and expanded abstracts published by English subprojects from six state universities and the federal university in Paraná in 2015 and 2016. The data was selected from the annals of the following academic events: $1^{\circ}$ PIBIDSUL / PARFORSUL / ENLICSUL, V SEMINÁRIO NACIONAL DO PIBID and VI CLAFPL. The theoretical framework that guided the data analysis were the studies about beliefs by Barcelos $(2004,2007)$, studies about metaphors by Lakoff and Johnson (1980) and the study by Audi et al (2013). The analysis confirmed the metaphors revealed by Audi et al (2013) and pointed out two more beliefs expressed by the metaphors TEXTUAL GENRES ARE THE REALITY and PLAYING IS LEARNING. Studies like this are important as they demonstrate how beliefs influence the processes of teaching/learning English an English teacher education. Another contribution is the mapping of studies about the English PIBID subprojects that in the last years has contributed to initial and continuing teacher education.

Keywords: PIBID. English. Teaching/learning. Teacher education. Beliefs and metaphors.

RESUMEN: Este artículo presenta las creencias, expresas o no por metáforas lingüísticas convencionales, sobre los procesos de enseñanza/aprendizaje de inglés y formación inicial y continuada de profesores de inglés en los subproyectos Programa Institucional de Bolsa de Iniciação à Docência (PIBID) Inglés y disponerlas dentro de metáforas conceptuales reveladas en el estudio de Audi et al. (2013). Los datos incluyen resúmenes y resúmenes expandidos publicados por los subproyectos PIBID Inglés de seis universidades públicas de la provincia de Paraná y de la Universidade Federal do Paraná en 2015 y2016. La generación de datos utilizó los anales de los siguientes eventos académicos: $1^{\circ}$ PIBIDSUL / PARFORSUL / ENLICSUL, V SEMINÁRIO NACIONAL DO PIBID y VI CLAFPL. El referencial teórico que sirvió de soporte para el análisis fueron los estudios sobre creencias de Barcelos (2004, 2007), en los estudios sobre metáforas de Lakoff y Johnson (1980) y en el estudio de Audi et al. (2013). El análisis corroboró las metáforas del estudio de Audi et al. (2013) y demostró la existencia de más dos creencias expresas en las metáforas LOS GÉNEROS TEXTUALES SON LA REALIDAD y JUGAR ES APRENDER. Estudios como este son importantes, pues demuestran cómo las creencias influyen en los procesos de enseñanza/aprendizaje de inglés y formación de profesores de inglés. Otra contribución de la investigación es mapear los estudios realizados sobre los subproyectos PIBID Inglés que en los últimos años han contribuido para la formación inicial y continuada de profesores.

Palabras clave: PIBID. Inglés. Enseñanza/aprendizaje de inglés. Formación de profesores. Creencias y metáforas. 


\section{Introdução}

O interesse em conhecer as crenças sobre formação inicial e continuada de professores de inglês no contexto dos subprojetos Programa Institucional de Bolsa de Iniciação à Docência - PIBID Paraná está ligado ao crescente desenvolvimento de pesquisas sobre os impactos deste programa na formação inicial e continuada de professores das mais diversas licenciaturas. O PIBID, programa coordenado pela CAPES (Coordenação de Aperfeiçoamento de Pessoal de Nível Superior) baseia-se na Lei no 11.502/2007 (BRASIL, 2007) e teve seus primeiros projetos implantados em $2010^{3}$. Os principais objetivos do programa são incentivar a formação de docentes que atuam na educação básica, contribuir para a valorização do magistério, melhorar a qualidade da formação inicial de professores das licenciaturas por meio da integração entre educação superior e educação básica, promover a inserção dos licenciandos no cotidiano de escolas públicas, além de possibilitar que os professores das escolas públicas atuem como coformadores dos futuros professores e contribuir para a articulação entre teoria e prática elevando a qualidade das ações acadêmicas das licenciaturas. Os subprojetos PIBID contam com 0 envolvimento de um professor coordenador de uma instituição de nível superior, um professor supervisor da escola parceira da rede pública e de acadêmicos das diversas licenciaturas. Todos os envolvidos são selecionados por meio de editais e recebem uma bolsa para desenvolverem atividades de ensino, pesquisa e extensão. O dado mais atual com relação ao número de projetos PIBID publicado no sítio da CAPES refere-se ao ano de 2014, quando o PIBID contava com 313 projetos em 284 universidades de todas as regiões do Brasil (CAPES, 2013).

O PIBID tem sido foco de pesquisas, por exemplo, as de Jordão (2013),

\footnotetext{
${ }^{3}$ Para maiores informações sobre o PIBID, acessar em http://www.capes.gov.br/educacaobasica/capespibid/pibid
} 
El Kadri (2014), El Kadri e Roth (2013), que estudaram os impactos do programa na formação inicial de alunos das licenciaturas. O estudo de Mulik (2014) analisa a contribuição do PIBID na formação continuada de professores da escola pública. Desta forma, este estudo, dentro das limitações de seu escopo, pretende contribuir para ampliar o mapeamento dos trabalhos sobre os subprojetos PIBID Inglês no Paraná, em particular sobre crenças sobre formação inicial e continuada de professores de inglês.

As crenças dos professores de inglês influenciam a formação das crenças de seus alunos, por exemplo, crenças sobre: o que é aprender inglês?, o que é ensinar inglês?, qual variedade da língua inglesa ensinar?, qual método utilizar?, como escolher o material didático adequado para determinado contexto?, é possível aprender inglês na escola pública?, é preciso ser um falante nativo para ser um bom professor de inglês?, entre outras. O grande número de publicações sobre o tema, tanto no cenário internacional (ZHENG, 2009, LARENAS; HERNANDEZ; NAVARRETE, 2015; ALIAKBARI; HEIDARZADIL, 2015, por exemplo) quanto no cenário nacional (ARAÚJO, 2004; BARCELOS, 2004; COELHO, 2005; BORGES et al., 2007; SANTOS, 2016; GUSMÃO, 2016), entre outros, demonstram o interesse crescente pelo tema.

A importância da identificação das crenças de professores de inglês e de seus alunos pode contribuir para a tomada de consciência de suas crenças e a consequente reflexão sobre o processo de ensino-aprendizagem de inglês em seus contextos (COELHO, 2005). Um aspecto importante nos estudos sobre crenças e ensino-aprendizagem de inglês é a origem das crenças, ou seja, não basta desvelar as crenças, é preciso ir além e analisar os fatores contextuais que influenciam a sua formação. Estudos apontam que as crenças dos professores têm origem nas suas experiências de aprendizagem (FÉLIX, 1999) e nas suas experiências de ensino (COELHO, 2005). Para Sakui e Gaies (1999), as crenças são entendidas como condicionadas situacionalmente, portanto, é possível dizer que as vivências nos cursos de formação inicial e/ou continuada 
também influenciam e estimulam o surgimento de crenças.

Outro tema tratado nesta pesquisa são as metáforas, em especial, as metáforas usadas conscientemente ou inconscientemente para expressar as crenças dos professores sobre os aspectos acima mencionados. Lakoff e Johnson (1980) em Metaphors We live By demonstram como as metáforas são instrumentos que nos ajudam a "entender e experimentar uma determinada coisa em termos de outra" (LAKOFF; JOHNSON, 1980, p. 5). Ou seja, as expressões têm funções cognitivas que estruturam nossas experiências. Lakoff e Johnson explicam que as metáforas linguísticas são usadas para termos acesso às conceituais, em outras palavras, as metáforas linguísticas nos ajudam a compreender as metáforas que estão na nossa mente e que não percebemos.

A formação profissional dos professores diz respeito à aquisição de conhecimentos específicos para as diferentes áreas do conhecimento, capacidades práticas além de atitudes indispensáveis para o exercício da profissão (LIMA; SILVA FILHO, 2013). Esta formação profissional se dá em diferentes etapas, sendo a primeira a formação inicial que se dá em particular, no interior das universidades, mais especificamente nos cursos de licenciatura. Inúmeros estudos sobre os cursos de formação inicial de professores de inglês têm sido desenvolvidos, uma vez que há uma preocupação permanente com a qualidade destes cursos e de seus egressos. Podemos citar Consolo (2003), Tazón Volpi (2006), Leffa (2006), Castro (2006); Martinez (2007), Alvarez (2010), Zamboni (2013), entre outros.

A formação continuada pode ser definida como a formação que ocorre após a formação inicial, no caso dos cursos de licenciatura, mas também aquela que incorpora a noção de continuum, ou seja, a formação que tem início formal nos cursos de licenciatura e se estende por toda a vida profissional dos professores.

A formação continuada de professores de inglês também tem sido foco de inúmeros estudos, como podemos ver em Mello (2009), Gimenez e Fogaça 
(2009) e Halu (2010). As pesquisas de Branco (2007), Costa (2004) e Fogaça e Gimenez (2010) destacam a escola como lócus da formação.

Perceber e transformar a escola em um dos lócus da formação inicial e continuada de professores é um dos pressupostos do PIBID, o que pode ser observado nos objetivos do programa:

[...] inserir os licenciandos no cotidiano de escolas da rede pública de educação, proporcionando-lhes oportunidades de criação e participação em experiências metodológicas, tecnológicas e práticas docentes de caráter inovador e interdisciplinar que busquem a superação de problemas identificados no processo de ensinoaprendizagem e incentivar escolas públicas de educação básica, mobilizando seus professores como coformadores dos futuros docentes e tornando-os protagonistas nos processos de formação inicial para o magistério (CAPES, 2008).

\section{Metodologia}

Esta pesquisa qualitativa foi realizada na forma de uma pesquisa bibliográfica (BORTONI-RICARDO, 2008) tendo como objetivo principal verificar as crenças sobre os processos de ensino/aprendizagem de inglês e formação inicial e continuada de professores de inglês e acomodá-las dentro de metáforas conceituais já reveladas, em particular no estudo de Audi et al. (2013).

A geração dos dados reuniu resumos e resumos expandidos publicados em 2015 e 2016 pelos subprojetos PIBID Inglês de seis universidades estaduais do estado do Paraná e da Universidade Federal do Paraná (vide quadro 1). Os textos foram selecionados nos anais de três eventos acadêmicos, a saber: $1^{0}$ PIBIDSUL / PARFORSUL / ENLICSUL - Seminário do PIBID Região Sul, Seminário da PARFOR Região Sul, Encontro das Licenciaturas Região Sul (2015) realizado de 7 a 9 de novembro de 2015 na UNIPLAC - Universidade do Planalto Catarinense, Lages, Santa Catarina com o tema Impacto na formação docente inicial e continuada; no V SEMINÁRIO NACIONAL DO PIBID realizado de 14 a 16 de setembro de 2016 na Pontifícia Universidade Católica do Paraná - PUCPR em Curitiba; o VI CLAFPL - Congresso Latino-Americano de Formação 
de Professores de Línguas, realizado de 25 a 27 outubro de 2016, sob o tema Diálogos (im)pertinentes entre formação de professores e aprendizagem de línguas na Universidade Estadual de Londrina - UEL.

A justificativa para a consulta dos anais destes eventos está relacionada ao período de interesse da pesquisa, ou seja, os anos de 2015 e 2016, porque os eventos representam a produção e participação em evento regional e nacional destinada à socialização de atividades e pesquisas dos subprojetos PIBID Inglês (PIBIDSUL e Seminário Nacional do PIBID) e o CLAFPL por ser um evento que trata de temas e pesquisas sobre questões relacionadas ao PIBID.

O referencial teórico que serviu de suporte para a análise foram os estudos de Lakoff e Johnson (1980) e o estudo de Audi et al. (2013) que demonstrou que as metáforas Metamorfose, Rompendo Barreiras e Mind the Gap ${ }^{4}$ foram utilizadas pelos participantes dos subprojetos PIBID Inglês ao avaliar as contribuições do programa para a formação inicial e continuada de professores.

É importante destacar que, apesar de terem sido utilizadas como guia de referência as metáforas Metamorfose, Rompendo Barreiras e Mind the Gap reveladas por Audi et al. (2013), durante a análise dos dados assumimos nossa subjetividade e a responsabilidade pelas interpretações, respeitando a natureza dos dados sem diferenciar "interpretação" de "análise" (CLIFORD, 1986 apud JORDÃO; FOGAÇA 2012).

\section{Metáforas, crenças e formação de professores: alguns conceitos}

Segundo Bowles (2005), o significado metafórico de uma palavra "...é o emprego de uma palavra ou locução que ordinariamente designa determinada coisa para designar outra". A palavra raiz no seu sentido literal pode ser usada para nos referirmos à raiz de uma planta, enquanto que seu sentido metafórico

\footnotetext{
${ }^{4}$ Importante mencionar que Audi et al. (2013) não segue o padrão dos estudos sobre metáforas, por isso as metáforas não estão grafadas em letras maiúsculas, nem seguem o padrão "X é Y".
} 
pode ser fazer referência à raiz de um problema (COLLINS..., 1995), por exemplo.

Bowles (2005) salienta que o uso das metáforas vai além da substituição de uma expressão literal ou que as metáforas são simples alternativas ao uso literal, o que sugeriria "que a cada expressão metafórica cabe uma contraparte literal" (BOWLES, 2005, p. 28). Uma função importante do uso das metáforas é a expressão de ideias e/ou conceitos de forma sucinta, econômica e compacta.

Os estudos mais recentes tratam das metáforas além da dimensão linguística, assim as metáforas são percebidas como "recursos conceituais para compreender ou criar a realidade ao invés de apenas descrevê-las" (KOVECSES, apud BOWLES, 2005, p. 25).

Lakoff e Johnson afirmam que:

\begin{abstract}
o sistema conceitual metafórico que rege nosso pensamento e nossas ações, faria com que as metáforas fossem uma fonte de evidência sobre o que as pessoas pensam e por que agem de certa maneira. Com base neste entendimento, a metáfora é um aparato cognitivo e está no próprio conceito do elemento metaforizado e não só nas palavras que 0 nomeiam, principalmente se considerarmos os conceitos abstratos que são, em sua maioria, metafóricos (LAKOFF; JOHNSON apud DE GRANDE, 2009, p. 48-49).
\end{abstract}

Tendo isto em mente, o acesso às metáforas conceituais é automático, ou seja, não é necessário esforço por parte dos falantes para compreendê-las, uma vez que a expressão metafórica aciona imediatamente a metáfora conceitual correspondente na mente do indivíduo (SARDINHA, 2007, p. 32-33).

Quando falamos de metáforas e formação de professores, Kleiman afirma:

[...] as metáforas são elementos que fazem parte do processo de familiarização do conceito cientifico na passagem do discurso científico para outros discursos, como o didático (KLEIMAN, apud DE GRANDE, 2009, p. 49). No processo de ensino/aprendizagem de formação de professores, a metáfora pode ser entendida como uma estratégia para o ensino de conceitos abstratos. Nesse sentido ela é, 'além de cognitiva, dialógica' (KLEIMAN apud DE GRANDE, 2009, p. 
49).

Muitos estudos têm se valido da análise das metáforas para entender o processo de formação de professores de inglês. Sabemos que a imagem faz parte do conhecimento pessoal prático do professor, descrito por Clandinin (1986 apud TELLES, 1999, p. 80) como um construto central para a compreensão deste conhecimento. Neste sentido, Bezerra et al. (2011) afirmam:

[...] é importante que o professor entre em contato com suas imagens e metáforas significativas, que tenha ligação com suas salas de aula, pois as mesmas funcionam como instrumentos de reflexão e representação do conhecimento do professor, o qual é construído com base na sua experiência pessoal e profissional. (BEZERRA et al., 2011, p. 201).

A afirmação de Bezerra et al. (2011) reforça a ideia de que as metáforas dão acesso ao nosso sistema conceitual e revelam como entendemos determinados conceitos, além de possibilitarem a reflexão sobre nossas experiências profissionais. A reflexão, por sua vez poderá produzir conhecimento e a conscientização sobre o processo de formação de professores e de ensino/aprendizagem de inglês. Em outras palavras, as metáforas podem ser usadas como forma de aprendizado sobre estes processos.

O estudo de Audi et al. (2013) analisa as metáforas utilizadas por um grupo de acadêmicos pibidianos em formação inicial do curso de Letras Inglês da Universidade do Estado da Bahia (UNEB), Campus X. As metáforas com relação às representações de transformações das identidades sugeridas pelos bolsistas nos três primeiros meses de participação no projeto foi denominada Metamorfose. A segunda categoria, denominada Rompendo Barreiras, diz respeito às relações sociais, de poder e hierarquias, e a terceira categoria, Mind the Gap, apresenta as representações sobre a estrutura universidade/escola e teoria/prática. 
Quadro 2 - Síntese das metáforas utilizadas pelos pibidianos

\begin{tabular}{|c|c|c|}
\hline \multicolumn{2}{|c|}{ A influência do Pibid nos processos de formação } \\
\hline Metáfora & Foco & Síntese das Análises \\
\hline Metamorfose & Identidades & $\begin{array}{c}\text { Transformação das } \\
\text { representações sobre a } \\
\text { profissão e transformação as } \\
\text { identidades. }\end{array}$ \\
\hline Rompendo Barreiras & Relações Sociais & $\begin{array}{c}\text { Questionamento das relações de } \\
\text { poder e ruptura de hierarquias. }\end{array}$ \\
\hline Mind the Gap & Universidade-escola & $\begin{array}{c}\text { Aproximação entre os mundos } \\
\text { da universidade e escola. }\end{array}$ \\
\hline
\end{tabular}

Fonte: Audi et al. (2013, p. 89).

É possível observar pela denominação das categorias do estudo de Audi et al. (2013) que o estudo analisou se e como os objetivos almejados pelo PIBID (vide página 2) foram atingidos.

Com relação aos estudos sobre crenças e aprendizagem de línguas, Barcelos (2007) afirma que eles se iniciaram "em meados dos anos 80 no exterior e em meados dos anos 90 no Brasil, com as defesas das primeiras dissertações sobre crenças em programas de pós-graduação em Linguística Aplicada (PUC-SP e UNICAMP)" (BARCELOS, 2007, p. 111).

Silva complementa o que diz Barcelos afirmando que:

o conceito de crenças fortificou-se na década de 90, a partir dos seguintes marcos teóricos: Leffa (1991), Carmagnani (1993), Almeida Filho (1993) e Barcelos (1995). Dentre os grandes nomes dos estudiosos supracitados, o que destacou-se foi o do pesquisador Almeida Filho (op. cit.), pois teorizou, pela primeira vez, em solo brasileiro na Linguística Aplicada sobre crenças ou abordagem/cultura de aprender no ensino e aprendizagem de línguas (BARCELOS, 2004). (SILVA apud GUSMÃO, 2016, p. 192).

Alguns dos termos utilizados para se referir às crenças sobre aprendizagem de línguas são:

[...] representações dos aprendizes (HOLEC, 1987); filosofia de aprendizagem de línguas dos aprendizes (ABRAHAM; VANN, 1987); conhecimento metacognitivo (WENDEN, 1986); crenças (WENDEN, 1986); crenças culturais (GARDNER, 1988); representações (RILEY, 1989, 1994); teorias folclórico-linguísticas de aprendizagem (MILLER; GINS-BERG, 1995); cultura de aprender línguas (BARCELOS, 1995); 
cultura de aprender (CORTAZZI; JIN, 1996); cultura de aprendizagem (RILEY, 1997); concepções de aprendizagem e crenças (BENSON; LOR, 1999; BARCELOS, 2004). (GUSMÃO, 2016, p. 192-193).

De acordo com Barcelos (2004, 2007), as crenças são sociais, uma vez que são uma forma de pensamento e transmitidas culturalmente; as crenças são também individuais, pois são uma forma de ver e perceber o mundo e seus fenômenos; as crenças são dinâmicas, pois podem se modificar ao longo do tempo e também são paradoxais, pois são sociais, porém individuais; dinâmicas, porém imutáveis.

Borg (2001) afirma que não há consenso sobre o significado do termo crença, mas que a compreensão de determinadas características contribuem para um melhor entendimento do termo. Algumas das características citadas por Borg (2001) são:

[...] o elemento verdade - com base em pesquisas sobre filosofia do conhecimento, uma crença é um estado mental que tem como seu conteúdo uma proposição que é aceita como verdadeira pelo indivíduo, embora o indivíduo possa reconhecer que outras pessoas têm outras crenças, a relação entre crenças e comportamento - a maioria das definições de crenças sugerem que as crenças orientam o pensamento e as ações das pessoas. Outro aspecto mencionado é a de que há crenças conscientes versus crenças inconscientes - este é um ponto que gera muita discordância, pois alguns afirmam que a inconsciência é um aspeto inerente na definição do termo, enquanto outros estudiosos entendem que um indivíduo pode ter consciência de uma determinada crença e não ter consciência sobre outras. (BORG, 2001, p. 186).

Exemplos de estudos sobre crenças e formação de professores são encontrados em Borges et al. (2007), Oliveira (2009) e Finardi e Dalvi (2013).

Como dito anteriormente, a formação inicial de professores tem como seu principal lócus a universidade, mais especificamente os cursos de licenciatura. No entanto, é válido destacar que a formação inicial deve ser entendida apenas como uma das etapas da formação que fornece orientações iniciais. Em geral, nos anos finais das licenciaturas, os acadêmicos têm contato com a realidade das escolas por meio dos estágios curriculares, dos projetos de 
extensão e, nos últimos anos, por meio da participação em programas como o PIBID, que preconiza que a escola seja vista também como um espaço importante da formação inicial e continuada de professores.

A discussão sobre formação de professores de inglês - ou de professores em geral - envolve a discussão sobre os paradigmas dos cursos de formação de professores. Para Wallace (1995), o ensino de língua inglesa é considerado uma profissão, pois se espera que professores de inglês possuam determinadas qualidades essenciais, como, por exemplo, uma base de conhecimento científico, um período de estudo rigoroso que é avaliado formalmente, um sentido de utilidade pública, padrões elevados de conduta profissional e a habilidade para desempenhar tarefas úteis e específicas de maneira competente.

Ainda de acordo com Wallace (1995), a profissionalização de professores pode se dar de acordo com três modelos de educação profissional: o modelo artesanal, o da ciência aplicada e o modelo reflexivo ${ }^{5}$.

Atualmente, a concepção de formação de professores é a de um processo contínuo, ou seja, os professores devem, idealmente, estar engajados num processo de formação permanente que se inicia formalmente nos cursos de licenciaturas, mas que deve continuar ao longo da atividade profissional por meio de cursos de pós-graduação, participação em pesquisas, participação em eventos acadêmicos, nos quais há a possibilidade de discussão e socialização de experiências, participação em grupos de estudos e em comunidades de prática. Outra modalidade de formação continuada que tem crescido nos últimos anos é a participação em programas como o PIBID, que reforçam que a formação tanto inicial quanto continuada se dá também no cotidiano da escola e da sala de aula.

De forma resumida, a formação de professores, aqui entendida como um

\footnotetext{
${ }^{5}$ Para detalhes sobre cada um destes modelo, consultar Wallace (1995), Zeichner (1993), Almeida e Gimenez (2010).
} 
processo contínuo, pode ser definida como:

[...] processo que possibilita, ao professor, alternativas para desenvolver no próprio trabalho docente, sua profissionalidade, conferindo a ele uma forma de agir e de solucionar problemas cotidianos, lançando mão de informações adquiridas ou daquelas fruto da reflexão com seus pares sobre a prática pedagógica. Assim, concebemos a formação continuada em sua definição dimensão mais ampla e mais relacionada a aspectos formativos formais e informais. (OLIVEIRA, 2009, p. 50).

A formação de professores nos moldes mencionados por Oliveira (2009) contribuiria para que os professores percebessem que a formação inicial não é suficiente, mas que precisam atualizar-se e aprender constantemente com seus pares para criarem situações desafiadoras para seus alunos. Professores não devem ser vistos e/ou sentirem-se técnicos, pois é necessário que tenham uma compreensão ampla e profunda do seu trabalho para poderem atuar com eficácia nas situações singulares e imprevistas do dia a dia. Além disso, é preciso lembrar que o conhecimento teórico sobre as questões de ensino/aprendizagem também não é suficiente - é preciso saber fazer, tomar decisões, bem como resolver problemas relacionados à pratica do dia a dia.

O interesse pela qualidade do ensino nas escolas públicas brasileiras é um tema de extrema relevância e está ligado à formação inicial e continuada de professores, de modo que é natural que os estudos sobre formação de professores seja objeto de inúmeras pesquisas e tema de eventos acadêmicos. Exemplos de estudos sobre formação inicial e continuada de professores no contexto brasileiro são encontrados em Mateus (2009), Halu (2010), Fogaça e Gimenez (2010), Gaffuri (2012), Jordão e Fogaça (2012), Oliveira e Lourenço (2015), entre outros.

Os estudos acima mencionados são todos relativos à formação inicial e/ou continuada de professores de inglês, no entanto, cada um tem um foco específico, o que demonstra o interesse e importância sobre os diversos aspectos relacionados ao tema. 


\section{Análise das crenças e metáforas formação de professores nas produções do PIBID inglês}

O objetivo da pesquisa era conhecer as crenças - expressas ou não por metáforas linguísticas convencionais - sobre formação de professores de inglês no contexto dos subprojetos PIBID Inglês (2015 e 2016) em algumas universidades estaduais do Paraná e na Universidade Federal do Paraná. Para tanto selecionamos resumos nos anais de três eventos (vide metodologia da pesquisa).

A análise dos resumos selecionados demonstrou que as crenças dos participantes dos subprojetos PIBID Inglês se enquadram na metáfora Mind the Gap, identificada no estudo de Audi et al. (2013). Como apresentado no quadro 2, esta metáfora tinha como foco a universidade-escola, no que diz respeito à aproximação da universidade e a escola.

Pudemos observar nos resumos analisados, que o PIBID, entendido como uma modalidade de formação inicial e continuada de professores, reforçou a crença de que a escola é o lócus de formação inicial e continuada que tem grande influência nas práticas docentes e nas reflexões sobre o processo de ensino/aprendizagem de inglês.

Assim, na síntese das análises apresentada por Audi et al. (2013) acrescentamos que, além da aproximação entre os mundos da universidade e escola, temos a escola como importante lócus da formação inicial de professores.

Acreditamos que é correto afirmar que a metáfora Metamorfose (AUDI et al., 2013), que tem como foco as identidades dos futuros professores e professores em serviço, também foi reforçada neste estudo e ocorreu porque a escola e os professores supervisores foram percebidos como parceiros essenciais desta metamorfose.

Já com relação à metáfora Rompendo Barreiras de Audi et al. (2013), 
com foco nas relações sociais, acreditamos que as avaliações encontradas nos resumos corroboram a crença de que os envolvidos sentiam-se e eram percebidos como parceiros, uma vez que houve interação durante as experiências vividas no PIBID, em especial quando do planejamento e execução e feedback sobre as atividades desenvolvidas nas escolas.

Nos resumos, pudemos observar que a metáfora Rompendo Barreiras, que tinha como foco as relações sociais que envolviam o PIBID, estavam presentes em alguns dos resumos e que eram expressão das crenças sobre a importância do PIBID com relação à aproximação da universidade e a escola pública.

A metáfora Mind the Gap com foco na dicotomia e aproximação universidade- escola também foi observada nos resumos e expressava a crença da importância do PIBID para a formação inicial e continuada dos participantes do PIBID.

Além das metáforas relacionados ao estudo de Audi et al. (2013), a análise demonstrou a existência de crenças sobre o papel do lúdico na aprendizagem do inglês e sobre o ensino/aprendizagem de inglês por meio dos gêneros textuais.

O quadro abaixo resume as crenças e as metáforas que expressam estas crenças.

Quadro 3 - Crenças e metáforas encontradas nos resumos

\begin{tabular}{|l|l|l|}
\hline \multicolumn{1}{|c|}{ Crenças } & \multicolumn{1}{|c|}{ Metáfora } & \multicolumn{1}{|c|}{ Foco } \\
\hline $\begin{array}{l}\text { Ensinar/aprender inglês por } \\
\text { meio dos gêneros textuais é } \\
\text { uma metodologia adequada }\end{array}$ & $\begin{array}{l}\text { OS GÊNEROS TEXTUAIS } \\
\text { SÃO A REALIDADE }\end{array}$ & $\begin{array}{l}\text { Ensino/aprendizagem de } \\
\text { inglês e os gêneros textuais } \\
\text { como metodologia }\end{array}$ \\
\hline $\begin{array}{l}\text { Aprender inglês deve ser } \\
\text { prazeroso e divertido }\end{array}$ & $\begin{array}{l}\text { JOGAR E TER PRAZER É } \\
\text { APRENDER }\end{array}$ & $\begin{array}{l}\text { Ensino/aprendizagem de } \\
\text { inglês e a importância do } \\
\text { lúdico }\end{array}$ \\
\hline
\end{tabular}

Fonte: Elaborado pela autora. 


\section{Considerações finais}

O objetivo do estudo era verificar as crenças dos professores em formação inicial e continuada sobre o processo de ensino/aprendizagem de inglês e sobre formação inicial e continuada que podem ser expressas por meio de metáforas linguísticas convencionais ou não no contexto do PIBID. Para tanto foram selecionados e analisados resumos e resumos expandidos de seis universidades estaduais do Paraná e da Universidade Federal do Paraná publicados em três eventos acadêmicos no $1^{\circ}$ PIBIDSUL / PARFORSUL / ENLICSUL, V SEMINÁRIO NACIONAL DO PIBID e VI CLAFPL. Os estudos de Lakoff e Johnson (1980) e de Audi e al (2013) serviram de apoio para a análise dos resumos.

O presente estudo corroborou as metáforas do estudo de Audi et al. (2013), ou seja, as metáforas que expressam as representações dos professores em formação inicial e continuada envolvidos no PIBID sobre as transformações de identidade - metáfora Metamorfose, as representações sobre as relações sociais, de poder e hierarquia e a metáfora Mind the Gap relacionada à estrutura universidade/escola e teoria e prática.

Além de corroborar o estudo de Audi et al. (2013), este estudo demonstrou a existência da crenças de que ensinar/aprender inglês por meio dos gêneros textuais é uma metodologia adequada e a de que aprender inglês deve ser prazeroso e divertido.

Acreditamos que os estudos teóricos, as discussões e reflexões desenvolvidas no PIBID sejam a origem destas crenças, uma vez que nos resumos temos as referências sobre tais temas. No entanto, especulamos que a interação com os professores e alunos nas escolas parceiras dos subprojetos PIBID também deram origem às crenças, além das experiências enquanto aprendizes.

A crença Ensinar/aprender inglês por meio dos gêneros textuais é uma metodologia adequada e foi resumida na metáfora OS GÊNEROS TEXTUAIS 
SÃO A REALIDADE, e a crença Aprender inglês deve ser prazeroso e divertido na metáfora JOGAR E TER PRAZER É APRENDER.

É importante reforçar a importância de estudos sobre crenças de professores para um melhor entendimento das práticas docentes e melhoria da aprendizagem dos alunos, em particular no contexto das escolas públicas que têm sido objeto de inúmeros estudos nos últimos anos.

Uma limitação do trabalho diz respeito ao tipo de material analisado, um estudo que incluísse entrevistas e/ou depoimentos dos envolvidos com os subprojetos PIBID Inglês forneceria mais dados sobre os temas estudados, mas não era o objetivo do estudo. Apesar desta limitação, acreditamos que foi possível contribuir com os estudos sobre os impactos do PIBID para a formação inicial de continuada dos professores de inglês.

Uma sugestão de pesquisa futura ainda no contexto do PIBID Inglês é a análise das crenças e metáforas sobre aprendizagem de inglês do ponto de vista dos alunos.

\section{Referências}

ALIAKBARI, Mohammad; HEIDARZADI, Mohsen. The relationship between EFL teachers' beliefs and actual practices of classroom management. Cogent Education, v. 2, n. 1, 2015.

ALMEIDA, Raquel; GIMENEZ, Telma Nunes. A necessidade do professor reflexivo para o uso crítico dos materiais de apoio ao ensino e à apre'ndizagem de língua estrangeira. Entretextos, Londrina, v. 10, p. 69-84, 2010.

ALVAREZ, Maria Luisa Ortíz. O papel dos cursos de Letras na formação dos professores de línguas: ontem, hoje e sempre. In: SILVA, Kleber A. Ensinar e aprender línguas na contemporaneidade: linhas e entrelinhas. Campinas: Pontes Editores, 2010.

ARAÚJO, Denise Rodrigues. Crenças de professores de inglês de escolas públicas sobre o papel do bom aprendiz. um estudo de caso. 2004. Dissertação (Mestrado) - Universidade Federal de Minas Gerais, Belo Horizonte, 2004.

AUDI, Luciana Cristina da Costa et al. PIBID de Língua Inglesa na UNEB campus X: algumas contribuições na formação docente. In: MATEUS, E. et al. (Org.). Experiências de formação de professores de Línguas e o PIBID. 
Campinas: Pontes, 2013.

BARCELOS, Ana Ferreira. Reflexões acerca da mudança de crenças sobre ensino e aprendizagem de línguas. Revista Brasileira de Linguística Aplicada, Belo Horizonte, v. 7, n. 2, 2007.

BARCELOS, Ana Maria Ferreira. Crenças sobre aprendizagem de línguas, linguística aplicada e ensino de línguas. Linguagem \& Ensino, Pelotas, v. 7, n. 1, p. 123-156, 2004.

BEZERRA, Daniella de Souza et al. (Formadores de) professores em formação: traduzindo ensino-aprendizagem de línguas em metáforas. In: SEMANA DE LICENCIATURA, 8., 2011, Jataí. Anais... Jataí: Instituto Federal de Educação, Ciência e Tecnologia de Goiás, 2011.

BORG, Michael. Teachers' beliefs. ELT Journal, Oxford, p. 186-188. 2001.

BORGES, Tatiane Diello et al. Crenças de uma professora de língua inglesa acerca do ensino/aprendizagem desse idioma. Entretextos, Londrina, v. 7, n. 1, jan./dez. 2007.

BORTONI-RICARDO, Stella Maris. O professor pesquisador: introdução à pesquisa qualitativa. São Paulo: Parábola Editorial, 2008.

BOWLES, Hein Leornad. Arqueologia da raiva e do entusiasmo: uma abordagem lexical. Ponta Grossa: UEPG, 2005.

BRANCO, Sandra. Meio Ambiente - educação ambiental na Educação Infantil e no Ensino Fundamental - Oficinas aprender fazendo. São Paulo: Cortez, 2007.

BRASIL. Lei no 11.502, de 11 de julho de 2007. Modifica as competências e a estrutura organizacional da fundação Coordenação de Aperfeiçoamento de Pessoal de Nível Superior - CAPES, de que trata a Lei no 8.405, de 9 de janeiro de 1992; e altera as Leis nos 8.405, de 9 de janeiro de 1992, e 11.273, de 6 de fevereiro de 2006, que autoriza a concessão de bolsas de estudo e de pesquisa a participantes de programas de formação inicial e continuada de professores para a educação básica. Disponível em: 5 maio 2017.

CAPES. Pibid: programa institucional de bolsa de iniciação à docência. 2008. Disponível em: <http://www.capes.gov.br/educacao-basica/capespibid>. Acesso em: 5 maio 2017.

CAPES. Relatórios e dados. 2013. Disponível em: <http://www.capes.gov.br/educacao-basica/capespibid/relatorios-e-dados>. Acesso em: 21 mar. 2016. 
CASTRO, Solange Teresinha Ricardo. Formação da competência do futuro professor de inglês. In: LEFFA, Vilson (Org.). O professor de línguas estrangeiras. Pelotas: EDUCAT, 2006. p. 7- 32.

COELHO, Hilda Simone Henriques. É possível aprender inglês na escola?: Crenças de professores e alunos sobre o ensino de inglês em escolas públicas. 2005. Dissertação (Mestrado) - Universidade Federal de Minas Gerais, Belo Horizonte, 2005.

COLLINS cobuild english guides 7: metaphor. London: The University of Birmingham, 1995.

CONGRESSO LATINO-AMERICANO DE FORMAÇÃO DE PROFESSORES DE LÍNGUAS, 6., 2016, Londrina. Anais... Londrina: Universidade Estadual de Londrina, 2016.

CONSOLO, Douglas Altamiro. Proficiência oral em língua inglesa (POLI) de professores de inglês como língua estrangeira. Relatório de pesquisa de pósdoutorado. Campinas: UNICAMP, 2003.

COSTA, Marisa Vorraber. Quando o pós-moderno invade a escola: um estudo sobre novos artefatos, identidades e práticas culturais. Projeto de pesquisa apoiado pelo CNPq. (2004-2007), Universidade de Lisboa, 2004.

DE GRANDE, Paula Bacarat. As metáforas conceituais e o ensino/ aprendizagem de conceitos em um curso de formação continuada. Instrumento: revista de estudo e pesquisa em educação, Juiz de Fora, v. 11, n. 1, jan./jun. 2009.

El KADRI, Michele Salles. English language teachers changing identities in a teaching practicum: PIBID and \{Coteaching| Cogenerative Dialogue as opportunities for professional learning. 2014. 353 fls. Tese (Doutorado em Estudo da Linguagem) - Universidade Estadual de Londrina, 2014.

El KADRI, Michele Salles; ROTH, Wolff-Michael. I Am a Pibidiana": Societal Relations as the Locus of Sustained Development in a Teacher Education Program in Brazil. Australian Journal of Teacher Education, Perth, v. 38, n. 5, p. 88-114, 2013.

FELIX, Ademilde. Crenças de duas professoras de uma escola pública sobre o processo de aprender língua estrangeira. In: ALMEIDA FILHO, J. C. P. (Org.). $O$ Professor de língua estrangeira em formação. Campinas: Pontes, 1999.

FINARDI, Kyria; DALVI, Maria Amélia. Crenças de professores de línguas sobre a formação inicial e continuada. Gláuks Online, Viçosa, v. 13, n. 1, p. 113-134, 2013. 
FOGAÇA, Francisco Carlos; GIMENEZ, Telma Nunes. Supervisão pedagógica em uma escola de idiomas: espaços de reflexão?. Revista $X$, Curitiba, v. 2, dez. 2010. Disponível em: <https://revistas.ufpr.br/revistax/article/view/ 24069>. Acesso em: 1 jun. 2018.

GAFFURI, Pricila. Rupturas e continuidades na formação de professores: um olhar para as práticas desenvolvidas por um grupo no contexto do PIBIDInglês/UEL. 2012. 141 f. Dissertação (Mestrado em Estudos da Linguagem) Universidade Estadual de Londrina, Londrina, 2012.

GIMENEZ, Telma Nunes; FOGAÇA, Francisco Carlos. Criando condições para o dsenvolvimento profissional continuado de professores de inglês: o Centro de Recursos do NAP. In: MATEUS, E.F.; QUEVEDO-CAMARGO, G.; GIMENEZ, T.. (Org.). Ressignificações na formação de professores. rupturas e continuidades. Londrina, PR: EDUEL, 2009, p. 13-30.

GUSMÃO, Graciene Verdécio de. Análise dos recursos semântico-discursivos de avaliatividade proferidos pelos alunos através de crenças. Revista de Estudos Acadêmicos de Letras, Cáceres, v. 9, n. 1, p. 189-201, 2016.

HALU, Regina Célia. Formação de formadoras de professoras de inglês em contexto de formação continuada (NAP-UFPR). 2010. Tese (Doutorado) Universidade Federal do Paraná, Curitiba, 2010.

JORDÃO, Clarissa Menezes et al. O PIBID- UFPR nas aulas de inglês. divisor de águas e formador de marés. Campinas: Pontes Editores, 2013.

JORDÃO, Clarissa Menezes; FOGAÇA, Francisco Carlos. Carvalhos, juncos, árvores e rizomas: paradigmas na formação de professores. Revista Brasileira de Linguística Aplicada, Belo Horizonte, v. 12, n. 3, p. 493-510, 2012.

LAKOFF, George; JOHNSON, Mark. Metaphors we live by. Chicago: University of Chicago Press, 1980.

LARENAS, Claudio Heraldo Díaz; HERNANDEZ, Paola Alarcón; NAVARRETE, Mabel Ortiz. A case study on EFL teachers' beliefs about the teaching and learning of English in public education. Porta Linguarum: revista internacional de didáctica de las lenguas extranjeras, La Rioja, v. 23, p. 171-186, 2015.

LEFFA, Vilson. Aspectos políticos da formação do professor de línguas estrangeiras. In: LEFFA, Vilson J. (Org.). O professor de línguas estrangeiras: construindo a profissão. Pelotas: Educat, 2006. v. 1, p. 333-355.

LIMA, Nayra Silva; SILVA FILHO, Marcelo Nicomedes dos Reis. A abordagem comunicativa no processo de aquisição de língua inglesa. Web-Revista 
Sociodialeto, Campo Grande, v. 3, n. 9, mar. 2013.

MARTINEZ, Juliana Zeggio. Uma leitura sobre concepções de língua e educação profissional de professores de língua inglesa. 2007. Dissertação (Mestrado) Universidade Federal do Paraná, Curitiba, 2007.

MATEUS, Elaine. Torres de babel e línguas de fogo: um pouco sobre pesquisa na formação de professores de inglês. Revista Brasileira de Linguística Aplicada, Belo Horizonte, v. 9, n. 1, p. 307-328, 2009.

MELLO, Heloísa Augusta Brito. Funções da alternância de línguas na sala de aula de segunda língua. Linguagem \& Ensino, Pelotas, v. 12, n.1, p. 135-164, jan./jun. 2009.

MULIK, Katia Bruginski. O programa institucional de bolsas de iniciação à docência (PIBID) como espaço de formação continuada de professores de língua inglesa. 2014. Dissertação (Mestrado em Letras: Estudos Linguísticos) Universidade Federal do Paraná, Curitiba, 2014.

OLIVEIRA, Ana Paula Gomes. Crenças de uma professora de língua inglesa: o papel do professor e as influências contextuais em foco. 2009. Dissertação (Mestrado) - Universidade de Brasília, Brasília, 2009.

OLIVEIRA, Anaís Andrea; LOURENÇO, Daiane da Silva. A formação continuada de professores de língua inglesa no paraná: percepções a partir de uma experiência. In: SEMINÁRIO NACIONAL INTERDISCIPLINAR EM EXPERIÊNCIAS EDUCATIVAS, 5., 2015, Cascavel. Anais... Cascavel: UNIOESTE, 2015.

PIBIDSUL, PARFOSUL, ENLICSUL: Impacto na formação docente inicial e continuada, 2015, Lages. Anais... Lages: [ s. n.], 2015.

SAKUI, Keiko; GAIES, Stephen. Investigating Japanese learners' beliefs about language learning. System, [S. I.], v. 27, n. 4, p. 473-492, 1999.

SANTOS, Deborah Regina Jotta Mendes. Crenças e expressões metafóricas nos discursos e práticas avaliativas de alunos e professores de língua inglesa. In: SAPPIL - ESTUDOS DE LINGUAGEM, 7., 2016, Niterói. Anais... Niterói: UFF, 2016.

SARDINHA, Tony Berber. Metáfora. São Paulo: Parábola Editorial, 2007.

TAZÓN VOLPI, Marina. A formação de professores de língua estrangeira frente aos novos enfoques de sua função docente. In: LEFFA, Vilson J. (Org.). $O$ professor de línguas estrangeiras. construindo a profissão. Pelotas: Educat, 2006. 
TELLES, João Antônio. O professor de línguas estrangeiras e seu conhecimento pessoal da prática: princípios e metáforas. Linguagem e Ensino, Pelotas, v. 2, n. 2, p. 29-60, 1999.

WALLACE, Michael John. Training foreign language teachers. a reflective approach. Cambridge: Cambridge University Press, 1995.

WENDEN, Anita. Helping language learners think about learning. ELT Journal, Oxford, v. 40, n. 1, p. 3-12, 1986.

ZAMBONI, Alessandra da Silva Quadros. A formação do professor de língua inglesa: um estudo interpretativo das ementas na formação inicial. 2013. Dissertação (Mestrado) - Universidade Federal do Paraná, Curitiba, 2013.

ZEICHNER, Kenneth. A formação reflexiva de professores: idéias e práticas. Lisboa: Educa, 1993.

ZHENG, He. A review of research on EFL pre-service teachers' beliefs and practices. Journal of Cambridge Studies, Cambridge, v. 4,n. 1, p. 73-81, Mar. 2009. 